\title{
O TEMPO DO TEXTO NO TEATRO
}

\section{Theresia Birkenhaver}

Dramaturga, doutora pela Universidade Livre de Berlim. De 2002 a 2005, foi professora de literatura alemã moderna, com foco em teatro, naUniversidade de Hamburgo. De 2005 até sua morte, em novembro de 2006 , lecionou Teoria e História do Teatro na Universidade de Artes de Berlim.

\section{Trad. Stephan Baumgörtel}

Mestre em Letras Inglês pela Universitat Munchen (LudwigMaximilians], doutor em Literaturas da lingua inglesa pela UFSC, com pós-doutorado na ECA/USP.

1 Originalmente uma palestra apresentada no colóquio Transformações Dramáticas na Universidade de Rouen publicada em 17 de novembro de 2005. O texto foi publicado posteriormente em Tigges, Stefan, Ed., Dramatische Transformationen. Zu gegenwärtigen Schreib- und Aufführungsstrategien im deutschsprachigen Theater. Bielefeld: transcript, 2008, p. 247-261. 


\begin{abstract}
Abertura
O contexto para discutir o tema "drama e teatro" tem mudado ultimamente. Até os anos 80 , no centro da discussão encontrava-se a relação entre texto e encenação: a questão sobre que liberdades a direção pode tomar em relação ao texto ou, dito de modo inverso, que humildade frente ao texto faz-se necessária. Mas hoje estão em questão outros aspectos: não mais o 'como' da encenação de um texto, mas o 'se', sua possibilidade em geral.
\end{abstract}

Podemos resumir, mesmo que um pouco esquematicamente, os distintos diagnósticos desse estado da seguinte forma:

1. O drama enquanto gênero literário com determinadas características há muito não é mais a forma literária privilegiada que interessa ao teatro. Faz tempo que não existem mais textos que seriam 'inaptos para o palco' por causa de suas particularidades formais. Textos em prosa, romances, epopeias, poemas, radiodramas: todo tipo de texto está sendo 'realizado' no palco, sem passar por uma 'dramatização' no sentido usual - podem ser tanto o Velho Testamento quanto o bestseller da última temporada, roteiros de filmes ou textos de autores famosos que não foram escritos para o palco. ${ }^{2}$

2. Ao mesmo tempo, as formas dramáticas se transformaram fundamentalmente e não podem mais ser classificadas por meio de características tradicionais do gênero - como estruturas dialógicas ou uma sequência de ações, diálogos e conflitos. No campo teórico, isso levou a uma conceitualização das características de textos dramáticos e não-mais dramáticos. Afirma-se uma cesura entre 0 teatro dramático - enquanto lugar de figuras que falam no contexto

\footnotetext{
2 Neste contexto, a variedade de realizações cênicas se estende da leitura cênica até a colagem eletro-acústica de palavras em forma de soundtrack, passando pela adaptação dramática.
} 
de ações ficcionais - e o teatro pós-dramático - enquanto lugar de discursos polifônicos e de significantes soltos. A essa concepção junta-se uma tese sobre a função da língua. No teatro dramático, assim ela diz, o texto apresenta os esboços de ação para um acontecimento ficcional e é texto de um personagem (portanto, fala figurativa). Textos teatrais além do drama, no entanto, mostram uma tematização autorreflexiva da língua. Desse modo, produzem-se oposições nítidas: aqui um teatro das palavras, ali um teatro dos corpos; aqui a representação fixada no texto, ali a presença performativa; aqui o sentido, ali o sensório.

3. Ao mesmo tempo, observa-se que o teatro começa a despedir-se completamente de textos. O happening e a performance, que foram exportados das artes visuais para o teatro nos anos 60 , não são mais fenômenos marginais. Determinam os programas de festivais e assumem um papel importante também na programação dos teatros institucionalmente subvencionados. Há um desaparecimento do texto, primeiro como elemento interno do fazer teatral, para depois sumir do teatro? Será que as causas desse processo são um ceticismo perante as possibilidades da língua, em favor de uma evidência maior da expressão corporal; um enfado frente a um "levantamento meramente intelectual"? Ou as dúvidas dizem respeito aos limites da simbolização e do dizível?

4. Entretanto, pode-se constatar que esse desdobramento tem recuado novamente: fala-se, desde os meados dos anos 90 , de uma volta do 'texto' e até de um redescobrimento ou de uma reciclagem dos elementos tradicionais da forma dramática. Os motivos para esse movimento são denominados de modo diverso: a reteatralização dos meios expressivos do palco se realizou ampla e plenamente por meio das estéticas teatrais que o século XX criou. Ou seja, este movimento se esgotou. Com as novas possibilidades tecnológicas, 
que permitem um jogo multiforme com a virtualidade dos corpos, das vozes e dos espaços, foi alcançada, assim se diz, a até agora última etapa desse desdobramento completo dos potenciais expressivos do palco. Como contraponto, então, cria-se um novo interesse em textos e na língua. Por outro lado, esse redescobrimento das formas do drama é relacionado com a realidade social modificada. Após os experimentos e jogos autorreferenciais dos anos 80 e 90, nos quais o teatro se referia, como se diz, somente a si mesmo, encontra-se hoje, frente às mudanças profundas nas sociedades ocidentais, novamente uma carência pela tematização de conflitos - e, com isso, a necessidade por formas dramáticas com ações, crises e catarse, como no caso de John von Düffel.

\section{Difusão: texto, drama, língua}

Independentemente dos modos como se queira avaliar essas tendências, 0 que se observa é uma erosão do terreno familiar. Eu quero me concentrar em um aspecto que pode ser percebido através de oscilações conceituais. Desde os anos 60 , multiplicam-se as propostas terminológicas para substituir o conceito de drama. "Substrato textual literário", "peça teatral", "textos teatrais", "literatura teatral", "textos de jogo/atuação", "matriz de jogo" ou agora bem simples: textos.

Algo semelhante vale para o conceito de figura: propõe-se falar de "portadores textuais", "instâncias discursivas" ou "instâncias locucionais".

O que se coloca em questão não é somente a autonomia literária do drama frente a uma prática de escrita a partir dos processos cênicos e junto a eles (ou seja, aproveitando uma pergunta de Sarah Kane: "Será que o teatro é mais exigente que as peças?"), mas também o lugar e a função do texto no teatro. Como se deve denominar aquilo que não é mais claramente um texto de personagem? Fala teatral, corpo verbal, verbo, poesia? 


\section{Müller: $O$ tempo de texto no teatro}

No contexto dessas perguntas, pensei em uma declaração de Heiner Müller feita durante uma entrevista com Robert Weimann: "[...] acredito que o tempo do texto no teatro ainda está por vir." ${ }^{3}$

Em 1989, esse depoimento é uma profecia estranha. Se não fosse o autor dessa frase Heiner Müller, cujas peças transformaram radicalmente o teatro, alguém poderia tomá-la como uma defesa obsoleta do princípio da fidelidade ao texto (na qual a exigência para a fidelidade para com o texto se une a concepções do teatro como uma prática fundamentada na palavra).

Naturalmente, é mais do que evidente que não se pode cooptar Heiner Müller para tal posição, de fato anacrônica. Por isso, a indagação de como a proclamação de Müller se diferencia de um teatro do texto, daquilo que se costuma chamar de teatro textocentrista e que alega, como se isso fosse algo evidente, pôr o texto no centro da apresentação.

Müller nega ao teatro exatamente essa reivindicação: ele chama a prática desse teatro baseado no literário de um modo de "administrar os textos". Sua conclusão é, por isso, radical: "Me parece que ainda não trabalhamos de fato com os textos no teatro."

"Ainda não trabalhamos de fato com os textos"... Müller descreve algum devir. Por isso, duas perguntas:

Como se pode pensar a relação entre texto e teatro de modo novo e além das dicotomias comumente estabelecidas?

E, antes disso: Por que Müller insiste no texto? O que é o texto?

\section{A realidade própria dos textos - não sua materialidade}

\footnotetext{
$3 \quad$ Heiner Müller, Robert Weimann: "Gleichzeitigkeit und Repräsentation. Ein Gespräch (1989). In Weimann, Robert \& Gumbrecht, Hans-Ulrich (org.) Postmoderne - globale Differenz, Frankfurt/Main, 1991, p.195.

lbid.
} 
No contexto da entrevista, Müller está aguçando suas considerações. Interessa-Ihe a "realidade própria dos textos":

"Não se reconhece o texto no teatro alemão. Somente é usado para fazer comunicados sobre a realidade. E isso é uma degradação dos textos, isso thes nega sua própria realidade."

E de modo mais radical ainda:

"O que me ocupa é a questão de como um texto pode se tornar realidade no palco, independente do ator que o diz."

O que ele quer dizer com isso? O que é "a realidade própria dos textos"?

A forma da colocação contradiz uma concepção que marcou o teatro europeu moderno desde o século XVIII. Nela, sempre tratou-se de fazer com que os textos (enquanto textos) desaparecessem: substituir a letra morta pelo movimento vivo, a artificialidade da escrita pela realidade dos corpos, a linearidade da frase pelo gesto singular, o preto-e-branco do traço gráfico da escrita pelo policromo do cenário.

A partir dessa concepção, surge a tradicional diferenciação entre os impactos da literatura e do teatro: textos necessitam do palco porque somente ali eles realizam o seu destino, enquanto fala de seres humanos vivos, enquanto locução de figuras ficcionais.

Nas frases de Müller, entretanto, se formula uma inversão: segundo ele, o teatro é um lugar para fazer com que os textos possam ser experimentados enquanto textos. Com isso, ele anula o entendimento corrente. Quando diz que textos dramáticos precisam do teatro, não o diz para afirmar que eles necessitam da fala enquanto meio expressivo (para tornar-se o que eles já são essencialmente: teatro), mas para poderem ser experimentados na sua própria realidade - enquanto textos.

Aparentemente essa qualidade não lhes pertence espontaneamente.

Frequentemente compreendeu-se a reivindicação de Müller como uma crítica a uma prática representacional que diminui o texto, por meio de sua interpretação, ao tamanho daquilo que se pode ainda pensar e representar. Concomitantemente, foi vista como uma escolha de outro tratamento do texto por parte do ator, que leva a sério os textos em sua materialidade, sua musicalidade e seu ritmo. No início dos anos 80, Robert Wilson foi um exemplo disso, e mais tarde o teatro do grupo Ângelus Novus (de Joseph Szeiler) ou de Einar Schleef. 
No entanto, sempre que Müller fala nesse sentido da melodia, da corporeidade e da physis, não é essa medialidade os meios expressivos genuínos do palco, com quais ele fundamenta a necessidade dos textos pelo teatro. Segundo ele, a questão deveria ser invertida. Não: por que é que textos precisam o teatro? Mas: por que o teatro é um lugar para textos? Em que sentido o palco permite uma experiência da realidade própria de textos que só é possível ali?

\section{Texto e teatro $=$ a temporalidade do texto}

Estou chegando ao segundo aspecto da colocação "o tempo do texto" no teatro: se refere também ao tempo que os textos recebem de parte do teatro. Isso não concerne unicamente aos modos temporais do palco - formas temporais encenadas, como duração, aceleração, repetição, alongamento, etc. - mas também ao tempo ao qual os textos são expostos através do teatro.

O teatro é, para Müller, menos uma máquina de expressões, senão uma relação temporal, na qual os mais diversos tempos estão presentes simultaneamente. Sua afirmação de que "a colisão (o drama) das camadas temporais do material do autor, dos atores e do público define o espaço vital [do teatro]" torna isso evidente.

O teatro confronta os textos com o seu próprio presente. Desse modo, são submetidos a uma perspectiva que não é a deles; são expostos a um segundo tempo. Mas exatamente isso remete à realidade específica e peculiar de textos: 0 fato de que eles possuem algo que excede seu próprio tempo histórico. Textos são exatamente isso: formas porosas que, enquanto língua sedimentada, abrigam diferentes camadas temporais - e com isso diferentes experiências.

Por isso, o teatro é um lugar necessário para textos, pois possibilita que eles encontrem aqui sua própria realidade, enquanto agregados que relacionam diferentes modos como pensamento e consciência se fazem presentes; uma realidade que eles não possuem se ficam isolados, pois essa realidade somente se configura na confrontação com o outro, com o tempo do outro.

\section{Desvio}


Duas ideias se entrelaçam aqui. Aos textos pertence uma estrutura temporal heterogênea, igual ao teatro: são agregados de tempo. Essa característica é fundamentada em sua configuração por meio da língua. A língua não é simplesmente um meio de que o sujeito dispõe para se expressar, mas, inversamente, ela constitui um espaço de experiências para o sujeito que a limita e também excede.

Neste sentido, textos nunca são somente comunicação que diz algo; seja este algo o estado do escritor ou informações sobre assuntos. Por meio do seu caráter linguístico, eles abrigam experiências que se localizam além das intenções do autor.

Müller reitera frequentemente que a língua não pertence a um ser singular: "eu não afirmaria que eu me apodero da língua. Paradoxalmente, acontece exatamente $o$ inverso: a língua se entrega a mim. A minha capacidade é ceder-lhe, menos que dominá-la." ${ }^{\circ}$

A língua é - como a memória - algo elusivo/indomável. Müller formulou isso às vezes com palavras lacônicas: "Escrevo mais do que sei. Escrevo em um outro tempo do que aquele em que vivo."

Exatamente essa realidade do texto enquanto língua que necessita do teatro para poder ser experimentada. Podem-se compreender as encenações como procedimentos que organizam um espaço no qual os diferentes tempos - o tempo do texto, dos atores/da encenação, do público - se encontram no presente da apresentação, se equilibram precariamente, se fracionam.

Encontram também aqui a inversão da compreensão familiar segundo a qual textos são material que precisa ser atualizado através de montagens que criam referências atuais. A prática de encenação do próprio Müller se coloca decididamente contra essa concepção, formada principalmente pelo chamado teatro dos diretores.

O teatro dos diretores se alicerça duplamente no modelo de autoria: primeiramente, pressupõe-se que os textos possuem uma mensagem e que, num segundo passo, é (ou deve ser) corrigida, afirmativamente modificada ou subversivamente ironizada pela encenação e a concepção da direção. Exatamente isso quer dizer: administrar textos.

A escolha de Müller, entretanto, é: os textos ganham presença não através de uma atualização na qual a orientação por um significado anterior (e pressuposto) é dominante, senão através de um movimento inverso: ao segui-los e descobrir o que 
está enclausurado neles, um pensamento desconhecido que não se comunica facilmente com o próprio tempo presente. Müller explicita isso com o exemplo de sua peça $O$ achatador de salários, que ele encenou em 1988 no Berliner Ensemble, quase trinta anos após sua estreia. A encenação descobre a realidade deste texto não através de uma concepção diretorial, que interpreta a peça novamente e a confronta com as condições de uma RDA naufragando, mas por partir "rigidamente do texto" (e seguir suas coerções). Desse modo, O achatador de salários se revela não como a peça de produção da RDA nos seus tempos iniciais, mas - assim diz Müller - como "diagnóstico de uma doença". "O texto sabia mais do que seu autor", assim o comentário.

O teatro é aquela prática que coloca textos numa situação que permite que eles se apresentem enquanto textos: texturas configuradas que não se limitam às intenções de seu autor. Assim, o teatro abre a possibilidade de renegar aquela concepção comum e inofensiva de textos que veem nele comunicados condensados e opiniões. (A crítica de Müller das peças parabólicas de Brecht possui sua razão aqui: se justifica pela crítica da intenção calculada.)

Exatamente isso é tema desta indagação de Müller: "Como se transforma um texto em hipopótamo?" Ou quando diz: "O texto é o coiote. E não se sabe como ele se comporta."

O texto é um animal - algo estranho, não-humano. A encenação tem a tarefa de organizar o processo por meio do qual os textos se tornam coiotes para o espectador; por meio do qual se pode vivenciar sua estranheza e o não-subjetivo deles. Um texto é, segundo Müller, "uma formação rochosa, um material que pode assumir aparências distintas, dependendo do ângulo da luz ou do tempo."9

$8 \quad$ Müller \& Weimann, p.195: "Encenar quer dizer tornar certo potencial do fenômeno 'texto' disponível à experiência: o não-subjetivo, sua estranheza, sua beleza, sua forma [...]." Em outro lugar, Müller enfatiza sobretudo o momento utópico da encenação da forma do texto: "A prática teatral é de tal modo que se transporta conteúdo, fazem-se comunicados por meio de textos. Mas não se comunica o texto, sua forma. [...] Não se comunica de modo algum que se trata de um texto configurado e que a formulação de um fato já é a superação do fato. O momento utópico reside na forma, também na elegância da forma, na beleza da forma e não no conteúdo." In: Müller, Heiner. "Der Weltuntergang ist zu einem modischen Problem geworden. [O apocalipse se tornou um problema de moda]. Ein Gespräch mit Uwe Wittstock." Gesammelt Irrtümer, Interviews und Gespräche I, Frankfurt/Main: Suhrkamp, p.180.

9 Da mesma forma, Müller reflete sobre a indagação escrita por Deleuze que formulara: "Escrever não é certamente impor uma forma (de expressão) a uma matéria vivida. [...] Escrever é 


\section{Os trabalhos de direção de Müller}

Não surpreende que Müller, enquanto diretor de seus próprios textos, tenha se recusado a utilizá-los para uma interpretação que os atualizasse, especialmente no caso de Mauser (1991) e Duelo, Trator, Fatzer (1993). Entretanto, segue como outra consequência de seus depoimentos que tampouco pode haver para Müller montagens modelos de suas peças. Os trabalhos de direção dele mostram isso. Das dez encenações que ele fez, quatro são repetições: ele monta duas vezes $A$ missão (1980 e 1982), duas vezes Quarteto (em 1991 como parte de Mauser, em 1994 como encenação independente), duas vezes O Findling (O achado/O errático) e duas vezes Wolokolamsker Chausee (em 1991 como parte de Mauser, em 1993 como parte de Duelo Trator Fatzer).

No caso dessas repetições, não se trata de uma multiplicidade de interpretações, nem de sua diversidade, mas do projeto de tornar impactante, de modo diverso, o potencial dos textos enquanto forma. Quero explicitar isso com o exemplo de Quarteto.

Em 1991, Quarteto formou a parte intermediária de uma noite que consistia em três peças: Mauser, Quarteto e Findling. A peça foi montada como um jogo teatral virtuoso com estrelas do Deutsches Theater - Dagmar Manzel e Jörg Gudzuhn -, que dominam soberanamente o jogo da troca de papéis e da camuflagem. Compreendeu-se essa abordagem como recaída em convenções representacionais do teatro de ator tradicional - e por isso como deslize estilístico. Entretanto, no contexto da encenação, essa característica é uma citação consciente: se expõe o jogo impecável com a ilusão, no qual o ator é completamente jogador. Ele próprio não sente nada, mas dissimula perfeitamente a impressão de uma naturalidade autêntica, ou seja, aquele ideal da atuação burguesa que está se criando na mesma época em que Choderlos de Laclos escreve o romance Les liaisons dangereuses.

O que se expõe é um modo de falar no qual qualquer diferença entre naturalidade fingida, dissimulação calculada e imitação bem-sucedida é uma ilusão grandiosa e

um caso de devir, sempre inacabado, sempre em via de fazer-se, e que extravasa qualquer matéria vivível ou vivida. É um processo, ou seja, uma passagem de Vida que atravessa o vivível e o vivido. A escrita é inseparável do devir: ao escrever, estamos num devir-mulher, num devir-animal ou vegetal, num devir-molécula, até num devir-imperceptível." (in Deleuze, Crítica e clínica. São Paulo: editora 34, 1997, p.11.) Müller se refere a Deleuze no prefácio de sua versão do Material Fatzer de Brecht: "A arte talvez seja a tentativa do devir-animal no sentido do livro de Deleuze e Guattari sobre Kafka." 
ao mesmo tempo um jogo sem fundamento, no qual se dissolvem sem distinção as identidades dos sexos, das figuras fantasiadas e reais.

Em suas três partes, a encenação faz uso de formas históricas do teatro: em Mauser da tragédia antiga, em Quarteto do drama burguês e em Findling da farsa grotesca.

Deste modo, é tematizada a relação entre subjetividade e língua, entre a fala individual e a língua enquanto estrutura objetiva. Essa relação determina a textura dos textos nos quais a identidade do locutor não pode ser claramente discernida. Quem ou o que fala, quando aparece, (em Mauser, como figuras A, B e um coro; em Quarteto, como uma figura ficcional de um romance, Valmont; em Findling, como uma figura fusionada de pai e filho) deve ser tratado como a fala de uma pessoa, de um coletivo? Falam seres vivos, mortos, humanos ou máquinas? Como se entrelaçam no dizer a fala subjetiva e a língua? ${ }^{10}$ Ao invés de atualizar os textos em seu potencial dramático, a encenação indaga nos distintos gestos linguísticos de todas as três partes as instâncias da fala e verifica se e como a fala pode ser atribuída a locutores, que seriam figuras e agiriam enquanto sujeitos de sua fala.

Um outro modo surge, então, na montagem de Quarteto em 1994 no Berliner Ensemble - com Marianne Hoppe e Martin Wuttke. A encenação realça o prazer no efeito retórico, na piada blasfêmica e na formulação ácida. Descobre-se em Quarteto uma fala que é movida pela presença da morte. A retórica do exagero comovente é destacada por meio de citações de formas melodramáticas canônicas: a atuação muda, o canto da heroína (ouve-se a canção Des Baches Wiegenlied, de Schubert, em cinco vozes no palco escuro), o quadro vivo cheio de significados.

A encenação também se apresenta como um jogo pomposo com as formas simbólicas de cerimônia, ritual e drama até o ponto no qual os reflexos mútuos não podem mais ser exacerbados e, num final grandioso, todo o cenário desaba e com ele o espaço das montagens refletidas uma na outra.

Exposto a diferentes tempos de presença, o texto Quarteto desdobra, de modo distinto, o potencial de sua forma - enquanto processo de reflexão.

Na encenação de 1991, é exposto um modo de falar enquanto dissimulação e enganação, simulação e jogo, que ergue um espaço hermético no qual não se pode mais distinguir entre comoção atuada e paixão encenada, entre morte real e fictícia.

10 E como se manifesta a língua? Enquanto sistema simbólico, força histórica, acontecimento poético, efeito retórico? 
A encenação de 1994, entretanto, expõe um tipo de falar que não diz nada; que se supera incessantemente em fórmulas retóricas; que busca intensificações que nunca chegam a um fim. Desse modo, mostra um modo de falar que é movimentado pela consciência da morte e que se deixa cessar.

Ambas as encenações tematizam o texto de modo diferente enquanto linguagem $e$ realizam assim uma dimensão do texto que se desprende da função representacional e comunicativa da fala dramática.

\section{O teatro enquanto prática de língua}

Müller devolve à percepção uma posição textual que ficou escondida por muito tempo pelas convenções cênicas de um teatro que pretendia servir ao texto. Este chamado teatro textocentrista criou uma prática na qual a cena foi vista como o lugar da discussão intersubjetiva e a língua/linguagem enquanto mimese de um fala individual. Assim, fez-se desaparecer uma estrutura de apresentação fundamental do teatro: a dupla perspectivação da fala dramática.

A simultaneidade de duas perspectivas é um fato fundador do teatro, nisso todas as teorias concordam. Ela é nomeada diferentemente: enquanto "dupla função" da fala dramática que se endereça sempre duplamente, à figura e ao público ${ }^{11}$; enquanto "sobreposição dos sistemas comunicativos interno e externo" ${ }^{12}$ e enquanto uma "separação latente entre os dois eixos de comunicação: a comunicação dentro da cena e para fora da cena, entre palco e espectadores." ${ }^{13}$ Mas quais são as consequências desse paralelismo para o texto?

Essa estrutura de apresentação expõe qualquer texto dito no palco a uma dupla perspectiva: nós o percebemos enquanto falar, enquanto fala de uma figura ficcional no contexto intradramático - aqui ele remete a um estar subjetivo, é expressão de uma figura - e simultaneamente estamos observando esse falar.

Dito de modo mais simples ainda: o palco é o lugar no qual se fala; o auditório é o lugar a partir do qual se vê e escuta esse falar. Por causa dessa estrutura bidimensional da apresentação teatral, qualquer falar no palco é, por um lado, ato de fala de uma figura, e, por outro lado, um falar percebido pelo espectador. Com

\footnotetext{
11 Larthomas, Pierre: Le langage dramatique. As nature, ces procédés. Paris, 1980, p.437.

12 Pfister, Manfred: Das Drama, München, 1988. p.24.

13 Lehmann, Hans-Thies. Postdramatisches Theater, p.230.
} 
isso, a fala teatral recebe um segundo ponto de referência: as frases faladas são tiradas de sua inserção exclusiva no contexto dramático; elas recebem um raio que vai além das figuras de modo que as palavras desenvolvem uma vida própria. As falas perdem seu sentido imediato, que se refere unicamente à situação dramática, e recebem espaços significativos que não Ihes pertencem enquanto réplicas singulares.

$\mathrm{Na}$ observação do falar, a própria língua se torna perceptível - em aspectos decididamente distintos: enquanto poder simbólico, enquanto memória solidificada, enquanto sistema de correspondências, enquanto campo de força metafórico, enquanto meio de comunicação ambíguo.

Dito de outro modo: por causa dos dois espaços heterogêneos - palco e plateia que o teatro liga, coexistem duas atitudes completamente opostas: a das figuras que falam e que ficam presas em suas intenções, e a dos espectadores, para os quais esse falar pode tornar-se perceptível em suas referências simbólicas, imaginárias e referenciais.

Se e através de quais formas essa relação dupla da fala é realizada - de modo explícito enquanto rompimento com o princípio da ilusão, ou escondida na estrutura dialógica que aparentemente se refere exclusivamente ao acontecimento representado -, isso depende de convenções dramatúrgicas e estético-teatrais.

Frequentemente, esse aspecto básico da apresentação teatral fica ofuscado: por causa da orientação não questionada na figura que fala e por causa da relação entre situação cênica e texto falado, como nas convenções cênicas do teatro textocentrista.

De forma alguma se tematiza o eixo palco-espectador, somente naqueles momentos nos quais há um endereçamento direto para o público, como nas formas teatrais da vanguarda e neovanguarda do século XX. Também os diálogos clássicos do drama não são exclusivamente atribuídos enquanto texto falado a dramatis personae. Enquanto textos para o teatro, eles sempre possuem uma referência dupla: em seus elementos, eles se referem a uma cena a ser representada, em seu cálculo compositório ao processo de apresentar, de ouvir e ver do espectador.

Mas isso cria consequências para nosso olhar sobre textos e encenações. No que concerne a textos dramáticos, isso significa não ler diálogos exclusivamente como referência a figuras; enquanto falas que Ihes caracterizam, Ihes dão um contorno, expressam seu estado emocional, etc., mas lê-los simultaneamente enquanto manifestações acerca de distintos aspectos da língua. 
Encenações devem ser interrogadas sobre como elas cruzam os dois eixos do teatro especificamente. Não raramente, o potencial de textos teatrais se reduz quando elas passam por cima do desdobramento da fala em diferentes perspectivas e camadas: por exemplo, quando um dos dramas de princesas de Elfried Jelinek, o texto Die Wand, é montado como se fosse uma troca de insultos entre figuras histéricas, como aconteceu ultimamente na montagem de Hans Neuenfels; ou quando o texto 4.48 Psícose, de Sarah Kane, é montado enquanto estudo sóciopsicológico do cotidiano num hospital psiquiátrico.

O teatro criou, ao longo de sua história, procedimentos bastante distintos para realizar aquele potencial de textos dramáticos, que uma leitura focada principalmente na ficção apresentada negligencia. São esses os meios genuínos de apresentação cênica que produzem essa dimensão verbal: o deslocamento do sentido das palavras por meio da imagem, de diferentes formas de espacialidade, da criação de diferentes temporalidades, de modos múltiplos de atuação.

É a perspectivação dupla inerente à estrutura da apresentação cênica que possibilita uma prática de língua específica ao teatro e ao formato do palco.

Ao invés de ser um lugar de encenar obras literárias, o palco se torna um lugar no qual com cada encenação surgem jogos de linguagem potencialmente novos.

Para Müller, a língua é história sedimentada, uma massa de significados, cujas sedimentações rompem nas encenações; os textos de Elfriede Jelinek tematizam a desapropriação da fala subjetiva na mimese de uma língua pública que é marcada consistentemente pelas retóricas da legitimação do poder. Seus textos precisam do teatro enquanto o lugar no qual pode se manifestar essa distância entre o falar dos sujeitos e da língua enquanto estrutura objetiva.

O que é próprio ao teatro não é nem uma relação específica nem determinados modos de falar. Ele é um lugar de experiências com a língua totalmente diferente. Seja esta experiência a da língua enquanto mascaramento, enquanto transgressão de retóricas, enquanto ambiguidade das palavras, enquanto extinção de significado, enquanto violência da fala ou polissemia das expressões verbais.

Conforme isso, a gama da imaginação literária no teatro está se ampliando. A língua aparece em formas que não podem mais ser relacionadas a convenções dramáticas. Textos aparecem como tessitura de infinitas formas de fala e de língua, que abrangem distintos horizontes ficcionais e não-ficcionais.

Nesse sentido, a observação de Müller ("eu penso que o tempo do texto no teatro ainda está por vir") não é em absoluto uma defesa restaurativa de um teatro de pura 
textualidade, baseado na palavra, mas, ao contrário, ela abre espaço para um teatro no qual se deve perceber a língua enquanto movimento do adensamento de sentidos, de produção de imagens e da atividade imaginária que se inicia com palavras, frases e a fala. 